diabetes is considered a worthwhile end by most humans (not least by those who are suffering from it) the working party concludes that such research is indeed worthwhile. However, costs may be reduced in terms of animal suffering if considerations of their needs in the laboratory environment are given necessary attention.

This case can serve as paradigmatic of the working party's approach. Thus, the perspective adopted involves considering the issues with a costs-and-benefits approach in mind. Broadly, one may say that the working party sees animal experimentation as a necessary but unfortunate course of action which must be accepted until alternative methods are found. In other words, certain specific differences between animals and humans are asserted 'from temporary (but by no means perpetual) necessity'.

Of course, total agreement on all aspects of detail is not reached by the working party. This is not surprising, given that eighteen individuals from diverse backgrounds are involved. What we are presented with, therefore, is an approach which is not wholly unified. Rather, we are faced with a volume which attempts to mediate between the interests not only of humans and animals, but also between the interests of humans who are themselves occasionally divided on the issues as a result of their own social interests, theoretical commitments and moral viewpoints. This makes the volume of special significance. For, however much one may feel the need to agree or disagree with its conclusions or specific points made, it is a book which will one day be of as much interest to future social theorists as to the present-day moral philosophers and scientists involved in the debate. In terms of its current value, one may say that the present study is useful reading for moral thinkers, research scientists and those concerned with the status of animals.

PETER SEDGWICK

University of Wales, College of Cardiff.

\section{Animal experimentation: the moral issues}

Edited by Robert $M$ Baird and Stuart E Rosenbaum, New York, Prometheus Books, 1992, 182 pages, $£ 9.50$
Is it justifiable to use animals for scientific research? The difficulty of responding to this question with a simple 'yes' or 'no' is well illustrated by the variety of perspectives represented by these sixteen essays. In their introduction to the volume, Baird and Rosenbaum provide a perceptive and open-minded summary of the positions adopted by their contributors. The contributions themselves, as I have already hinted, often diverge considerably from one another. Robert B White's 'Beastly Questions', for example, presents a strongly emotive case for animal experimentation, achieved by way of reference to the human suffering that has been prevented as a result of its use. On the other side of the argument, Richard Ryder's essay, 'Speciesism', attempts to dissolve the assumed differences which are traditionally thought to separate humans from animals. According to Ryder, we are just (albeit 'very clever') animals. Recognition of this fact, moreover, should oblige us to conclude that if we are part of the same biological system, then why not accept the fact that we also share the same 'moral continuum'? Indeed, Ryder goes to the extreme of asserting that anyone who denies this view is guilty of 'as great a prejudice as racism'. For Carl Cohen, however, the view that 'speciesism' is akin to racism 'is worse than unsound; it is atrocious'. Cohen asserts that since animals can neither make nor respond to moral claims, it makes no sense to assume that they have any rights. As humans we have certain ethical obligations which should govern our treatment of animals, but all species are not equal and animal experimentation needs to be defended from this viewpoint. J A Gray, too, sees 'speciesism' as both necessary and justifiable. Tom Regan, in contrast, having found utilitarian arguments an insufficient basis for protecting animals, argues for a model of animal rights based upon a principle which holds all 'experiencing subjects of life' to have an 'inherent value'. Defining what one means by the term 'inherent value', however, is a problem for Mary Anne Warren. As she notes, the notion must either be grounded in some 'natural property' or be arbitrary and therefore unpersuasive. If it is the former, then that natural property itself would require definition and should be the starting point for a defence of animal rights, which in turn begs the question as to the primacy of the concept of inherent value.

Two of Peter Singer's essays are included. In 'The Significance of Animal Suffering' he argues for an ethical principle which can be adopted for the purposes of minimizing human and non-human distress alike. If a thing can suffer, says Singer, we must assume that it deserves the same treatment as we would conventionally reserve for human beings. Hence, in arriving at a moral judgement the potential suffering of an animal must have the same weight in our deliberations as the potential suffering of a person. However, as William Timberlane asserts in reply to Singer, providing an adequate definition of suffering is a far from easy task.

Alan Freeman and Betty Mensch provide the closing piece for the volume. Their contribution constitutes an attempt to think beyond the contradictions and aporias which they see as dominating the debate. For Freeman and Mensch, what needs to be questioned is the dominance of western discourse, 'which may be characterized [as the discourse of] dualistic, analytic, [and] instrumental rationality'. The philosophical tradition inaugurated by the work of Bacon and Descartes is singled out here, their 'legacy pervades the modern psychology lab'. However, Freeman and Mensch do not arrive at a position which advocates the wholesale abandonment of animal experiments, in fact they resist any temptation to offer 'prescriptive norms'. Instead, a 'postmodern' practice is advocated. Freeman and Mensch, however, seem to have a rather ill-defined notion of what the term 'postmodern' means. For them, it is equated with a 'theological agenda' which hardly seems to reflect the work of those generally taken to be representative of postmodernism itself (that of JeanFrançois Lyotard, for instance). Nor, it follows, are they very conscious of the problems which beset anyone intent on following the postmodern trail.

In spite of such minor reservations, however, each piece (including those I have not had the space to mention) represents a useful and illuminating reflection on the problems. The basic positions and arguments are well represented, and this book can be commended to all those with an interest in the issues.

PETER R SEDGWICK University of Wales, Cardiff. 